\title{
RBEP
}

\section{Explicadoras do Rio de Janeiro: encontros e desencontros em trajetórias profissionais singulares*}

Luiz Otavio Neves Mattos

\section{Resumo}

Trata-se de estudo de natureza empírica, com inspiração etnográfica e que tencionou analisar as trajetórias de nove explicadoras, ou melhor, professoras que lecionavam nas suas próprias residências, em locais como salas de jantar, varandas e quintais, para turmas multisseriadas compostas por alunos que estudavam, na sua maioria, da classe de alfabetização à oitava série. Três questões nucleares compuseram o eixo central investigativo do estudo: a) O que eram as explicadoras? b) Como se deram seus processos de socialização na direção do magistério e, posteriormente, do magistério doméstico? e b) Como atuavam nos seus espaços de trabalho? Procedeu-se no início do estudo a uma revisão dos trabalhos do campo da História da Profissão Docente, com o intuito de situá-lo como tal e, por conseguinte, defini-lo como um estudo de um tipo de exercício da docência. Em seguida, a pesquisa apresentou, com riqueza de detalhes, os principais dados colhidos no decorrer das entrevistas exploratórias, das observações participantes e das entrevistas semi-estruturadas - todos esses, instrumentos metodológicos acionados na condução do trabalho de campo. Os processos de socialização das nove professoras, inicialmente na direção do magistério e, posteriormente, na direção do trabalho como explicadoras, foram analisados à luz dos conceitos de habitus e estratégia elaborados por Pierre Bourdieu e interpretados na pesquisa por Nogueira, Lelis e

* Este artigo é fruto de minha tese de doutoramento, de mesmo título, defendida em 5 de abril de 2006 na Feusp. A realização da pesquisa se deu entre os anos de 2004 e 2006. 
Perrenoud. Os resultados sugerem que, dentro das condições materiais de existência das nove explicadoras, o magistério se configurou como saída possível para suas aspirações profissionais, enquanto que o ofício de explicadora reunia, para elas, condições práticas ideais, uma vez que garantia proventos mensais sem nenhum tipo de desconto e, principalmente, a possibilidade de exercer um ofício podendo administrar o lar e acompanhar de perto os filhos. Com relação à terceira questão da pesquisa, sete eixos temáticos foram forjados a partir da potência dos dados oriundos da empiria. Foram eles: as estratégias didáticas utilizadas pelas explicadoras; as rotinas criadas por elas para darem conta das demandas diárias dos alunos; os recursos por elas acionados para conseguirem atender as variadas solicitações oriundas da pluralidade de seus atendimentos; as relações travadas por elas com as famílias, escolas e alunos; a visão que cada uma delas tinha sobre escola, família e aluno; as diferenças que marcavam o êxito de suas intervenções junto aos alunos se comparadas às escolas e, por último, os sonhos e desejos alimentados por todas elas como mulheres e professoras - todos apontando para o perfil de uma modalidade de exercício da docência e para a singularidade de experiências vividas a partir das histórias individuais de nove mulheres. Cabe ressaltar que o estudo teve condições de detectar um certo esgotamento das possibilidades das famílias em acompanharem a demanda de tarefas propostas pelas escolas para os alunos.

Palavras-chave: história da profissão docente, práticas docentes, magistério, docência, tipos de exercício da docência, modos de atuação no magistério, explicadoras.

\section{Abstract \\ "Explicators" of Rio de Janeiro: encounters and disencounters in sin- gular professional trajectories}

The study is of an empirical nature, with ethnographic inspiration and it intended to analyze the trajectories of nine "explicators", better saying, teachers who teach in their own residences, in dining rooms, balconies and yards, for classes with students from pre-school to primary school. Three core questions composed the central axis of the study: a) who were the "explicators"? b) how were their processes of socialization in teaching and, later, in home teaching? and c) how they acted in their work environment? In the beginning of the study, one made a revision of the works in the History of Teaching, with the intention to point it out as such and, therefore, define it as a study of a kind of teaching. After that, the research presented, rich in details, the main data gathered from the interviews, from the observations and from the half-structuralized interviews - all these, methodological instruments concerning fieldwork. The processes of socialization of the nine teachers, initially in the school direction, and, later, in the direction of the work as explicators, were analyzed in the light of the concepts of habitus and strategy elaborated by Pierre Bourdieu and interpreted in the research by Nogueira, Lelis and Perrenoud. The results suggest that, within the material conditions of the nine explicators, teaching was a viable 
path for their professional aspirations, while being an explicator meant, for them, the ideal practical conditions, since they could earn money without tax discounting and, mainly, the possibility to work and to be able to manage their homes and to take care of their children. In relation to the third question of the research, seven thematic axes were forged from the deriving data from the empirics. They are the following: the didactic strategies used by the explicators; the routines created for them to manage the daily demands of the students; the resources set for them in order to take care of the requests deriving from the plurality of their teaching; their relationship with the families, schools and students; the vision that each one of them had about school, family and student; the differences that marked the success of their interventions together with the students when compared to the schools and, finally, their dreams and desires as women and teachers - all pointing to the profile of teaching and to the singularity of experiences lived by the individual histories of nine women. One should point out that the study was in condition to detect a certain exhaustion of the possibilities concerning the fact that the families could not follow the demand of tasks proposed for the students by the schools.

Keywords: history of teaching, teachers' practices, teaching, ways of teaching, explicators.

Não é exagero afirmarmos que um número expressivo de pesquisas realizadas no campo da Educação tem como ponto de partida as práticas cotidianas de seus autores.

É possível, também, afirmarmos que estudos dessa natureza têm sofrido severas críticas no universo acadêmico, por se limitarem, muitas vezes, a pretensões pragmáticas, com poucas possibilidades de universalização e diálogo entre seus resultados e outras realidades potencialmente próximas, ou correlatas, no âmbito da pesquisa em Educação.

No entanto, esses mesmos estudos (salvo algumas produções de baixa qualidade) têm conseguido gerar conhecimentos de fundamental importância para compreendermos melhor o universo da cultura escolar, das práticas pedagógicas, da formação dos professores, do ofício dos alunos, da relação família-escola; enfim, de uma quantidade generosa de temas que, se abordados sem um mergulho profundo e responsável naquelas realidades, tendem a fragilizar seus pretensos resultados e conclusões.

Pois bem, este artigo fala de um estudo que nasce de uma realidade vivida por muitos professores (entre os quais me incluo) em seus cotidianos.

Mas de que realidade estou a falar?

Não são poucos os docentes que vêm produzindo pesquisas que se dedicam a investigar a respeito do "fracasso escolar" dos alunos.

Vários estudos vêm concorrendo, há pelo menos quatro décadas, ${ }^{1}$ para explicar esse tema. $\overline{{ }^{1} \text { Sobre esse tema, consultar Patto }}$ (1999). 
Entretanto, a pesquisa da qual trata o presente artigo faz uma opção teórica que não compreende o fracasso escolar como um objeto de estudo e, para sustentar tal decisão, vai buscar consistência junto aos estudos desenvolvidos por Bernard Charlot, que pretendem abordar, segundo ele, "[...] uma questão antiga de uma forma relativamente nova" (Charlot, 2000, p. 9).

Para Charlot (2000, p. 9) a questão do fracasso escolar se configura em "[...] um campo saturado de teorias construídas e opiniões de senso comum" e, para dar conta dela, ele procurou abordar "[...] essa questão clássica na perspectiva da relação com o saber e a escola".

Charlot (2000, p. 16) não se nega a reconhecer que existem

[...] alunos que não conseguem acompanhar o ensino que lhes é dispensado, que não adquirem os saberes que supostamente deveriam adquirir, que não constroem certas competências, que não são orientados para a habilitação que desejariam, alunos que naufragam e reagem com condutas de retração, desordem, agressão.

Entretanto, continua ele: "É o conjunto desses fenômenos, observáveis, comprovados, que a opinião, a mídia, os docentes agrupam sob o nome de 'fracasso escolar'."

Portanto, foi nessa direção que passei a ajustar o ponto de partida dessa pesquisa, ou melhor, na direção do que Charlot (2000, p. 16) chama a atenção: "O 'fracasso escolar' não existe; o que existe são alunos em situação de fracasso."

Nesse sentido, pude dar um tratamento mais adequado, sob o ponto de vista teórico, para as angústias de um professor, como eu, que não se conformava com o sucesso de alguns alunos e o insucesso de vários outros.

\section{Ao observar a relação família-escola, o (re)encontro com as explicadoras ${ }^{2}$}

Se esse estudo nasce do meu inconformismo com as situações de fracasso escolar de alguns alunos e com o sucesso de outros, ele se desenvolve e amadurece a partir do deslocamento do seu foco para certas estratégias familiares usadas como formas de evitar o insucesso escolar de seus respectivos filhos.

A mudança da direção do meu olhar me fez encontrar, ou talvez reencontrar, a figura das explicadoras, mulheres que, com suas histórias e práticas "tomaram de assalto" minha pesquisa.

Digo isso porque a pretensão inicial do estudo era a de mergulhar no universo existente entre famílias, escolas e explicadoras para procurar entender essa rede de relações paralela ao sistema escolar formal mas, ao mesmo tempo, tão conhecida por ele.

Na depuração do objeto de estudo acabei por me seduzir pelas trajetórias das explicadoras.

O reencontro com elas [as explicadoras] deve-se ao fato de que nasci e fui criado, durante 28 anos de minha vida, no bairro onde foi feita a pesquisa. A convivência com a realidade dessas mulheres que exerciam o magistério 
"doméstico" fez parte do meu cotidiano, isso porque minha irmã mais velha, meu irmão caçula e eu fomos alunos de uma explicadora, ${ }^{3}$ no período de nossa escolarização primária, em Vila Valqueire. ${ }^{4}$ Some-se a esse episódio o fato de minha irmã (professora primária e pedagoga) ter exercido o ofício de explicadora durante vários anos em sua casa.

Ajustes feitos, objeto redimensionado, a definição dos interlocutores teóricos passou, então, a ocupar lugar central no cronograma da pesquisa.

Os estudos voltados para o campo da História da Profissão Docente se credenciaram, como opção mais adequada, para o diálogo teórico necessário com o intuito de situar o tema das explicadoras no cenário da produção existente da pesquisa em Educação.

Figurou como central nesse diálogo inicial o livro 500 anos de educação no Brasil, organizado por Eliane Marta Teixeira Lopes, Luciano Mendes de Faria Filho e Cynthia Greive Veiga (2003).

A partir do trabalho de Denice B. Catani (2003), intitulado "Estudos de História da Profissão Docente", no qual a autora tenciona examinar convergências existentes nas produções sobre história da profissão docente no Brasil, foi possível identificar a ausência de estudos dedicados a investigar os modos de atuação (Catani, 2003, p. 589) presentes no magistério brasileiro.

Esse foi um movimento decisivo para o tratamento que passou a ser dado às explicadoras na pesquisa.

Explicando melhor, o ofício de explicadora passou a ser tratado na pesquisa como uma forma de exercício da docência.

No sentido de dar mais consistência à revisão da bibliografia que guardasse interfaces com o meu objeto de estudo, recorri, então, a três fontes.

Em primeiro lugar, busquei nas dissertações de mestrado e teses de doutorado das bibliotecas virtuais da PUC-SP, PUC-Rio, USP, UFMG, Unicamp e UFSM temas relacionados com as práticas docentes/práticas pedagógicas, a história do magistério/história da profissão docente, a profissão/ profissionalização docente, as trajetórias de professoras, a identidade profissional e com os saberes docentes.

Em segundo lugar, trabalhos publicados em periódicos com boa circulação nacional - Cadernos Cedes (Unicamp), Cadernos de Pesquisa (Fundação Carlos Chagas), Revista Educação e Pesquisa (Feusp), Educação e Sociedade (Unicamp), Revista Brasileira de Educação (ANPEd) e Educação (UFSM) -, também foram selecionados para leitura a partir dos eixos temáticos norteadores da busca.

Por último, o CD-ROM da ANPEd com produções de 1981 a 1998 e os CDs-ROM das reuniões realizadas em 1999, 2000, 2001, 2002, 2003 e 2004 foram igualmente explorados a partir do uso de descritores e títuloschave: História da Educação, Professoras e Professores, Professores Primários, Trabalhadores em Educação, Docentes e Docência, Trajetórias.

É importante ressaltar que toda essa busca e posterior leitura confirmou o que chamei na tese de um "buraco" existente na produção daquele período explorado, no que diz respeito às formas de exercício da docência ou, como tratado por Catani (2000, p. 589), modos de atuação no magistério.

\footnotetext{
"Tia Conceição", uma das nove explicadoras pesquisadas.

${ }^{4}$ Bairro situado na zona oeste do Rio de Janeiro, mais especificamente na região de Jacarepaguá, onde meus familiares (mãe, irmãos, sobrinhos, tios, primos, cunhados, afilhados, etc.) residem até hoje. Assim como em outros bairros da periferia do Rio de Janeiro, Vila Valqueire possui um número bastante grande de casas que anunciam, por meio de placas em suas fachadas, os serviços de explicadoras.
} 
Portanto, o perfil inaugural do estudo vislumbrava a dificuldade de uma interlocução teórica mais direta, ou melhor, a situação demandava um esforço de busca e ampliação de diálogo.

O bom manuseio das fontes selecionadas no processo de revisão bibliográfica e o contato com o campo foram determinantes para a superação das ausências apontadas.

Falemos, então, do campo.

\section{A preparação para a entrada}

Quatro critérios foram definidos para o início do trabalho de campo. Foram eles: a heterogeneidade das informantes (as explicadoras), o local onde se realizaria a pesquisa, o campo de atuação das informantes e o número de sujeitos com o qual a pesquisa iria contar.

O critério da heterogeneidade procurou dar conta da pluralidade existente no universo das explicadoras: pluralidade expressa na formação escolar e profissional, na origem familiar, no tempo de exercício no magistério escolar e/ou doméstico, no tempo de formação, na idade, no pertencimento geracional e no capital cultural e intelectual das informantes e de suas famílias.

O local de realização da pesquisa, outro importante critério definido para a entrada no campo, levou em consideração a minha facilidade de deslocamento entre as casas das explicadoras. O bairro escolhido - Vila Valqueire tinha características muito semelhantes aos demais bairros da periferia da capital fluminense no que se refere à existência das explicadoras, fator esse que contribuiu para a concentração do trabalho de campo em uma região sobre a qual eu tinha maior conhecimento.

O campo de atuação das explicadoras figurou entre os critérios, por possibilitar a delimitação do tipo de atendimento feito por elas; isto é, foram investigadas professoras que trabalhavam preferencialmente com o primeiro segmento do ensino fundamental e, no máximo, com alunos cursando até a oitava série.

Por último, mas não menos importante, o número de informantes se configurou - como em todos os estudos de natureza qualitativa, que lidam com entrevistas e observações - em um critério estratégico para o trabalho de campo.

Pensado inicialmente para serem seis os informantes, cheguei ao número de nove explicadoras, em virtude da pluralidade de perfis encontrados nas primeiras visitas ao campo.

Cabe lembrar que planejei, então, contar com dez sujeitos para fazerem parte do grupo da pesquisa - nove mulheres e um homem -; entretanto, em conseqüência de um problema de saúde, o único homem no grupo de explicadores teve que sofrer uma cirurgia de emergência e permaneceu internado durante toda a realização da pesquisa de campo.

\section{Os primeiros contatos e a definição do grupo}

Em Vila Valqueire - ou "no Valqueire", como é mais conhecido o bairro - não é difícil encontrarmos casas que ofereçam serviços de explicadoras. 
Andando pelas ruas, ainda arborizadas, desse que se caracteriza como um dos bairros residenciais do Rio de Janeiro, é possível encontrarmos diversas placas nas janelas e fachadas anunciando:

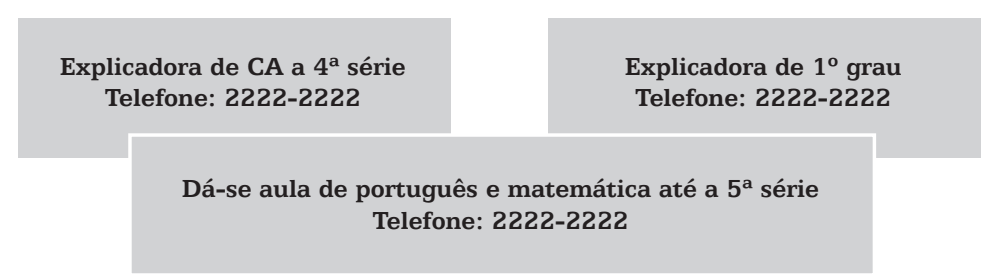

Pois bem, foi tocando a campainha dessas residências, ou anotando os telefones para posterior contato, que iniciei as primeiras abordagens junto às explicadoras.

Entretanto, dois aspectos devem ser ressaltados.

O primeiro diz respeito a uma das explicadoras, na verdade a mais idosa do grupo: D. Conceição, ou "tia Conceição", como era chamada por nós lá de casa.

Refiro-me a ela porque, por ocasião da pesquisa, o primeiro contato com Conceição já completava mais de trinta anos. Fomos todos - eu, meu irmão caçula e minha irmã mais velha - alunos dessa explicadora, que estava aposentada desde 1985. Meu irmão, inclusive, alfabetizou-se com ela.

Dessa forma, com exceção de Conceição, todos os outros contatos partiram do "zero", ou melhor, das "placas".

E é aí que entra o segundo aspecto sublinhado anteriormente: para aproximar-me das outras oito explicadoras que compuseram a pesquisa, contei com a participação de uma colaboradora bastante especial: D. Ivette, minha mãe.

Em virtude das orientações médicas e dos conselhos do filho - professor de Educação Física -, D. Ivette caminhava (e continua caminhando) pelas ruas do bairro com uma tarefa que ia além do exercício físico: descobrir novas placas e repassar os respectivos telefones e endereços para mim.

Pode parecer bizarro ou pouco comum no universo acadêmico, mas foi uma tática certeira.

Digo isso porque, na maioria das vezes, D. Ivette batia na porta dessas casas e se apresentava como a mãe de um pesquisador da USP, que tinha pretensões de pesquisar sobre as explicadoras de Vila Valqueire e que precisava da autorização delas para proceder a um primeiro contato.

Certamente que houve intencionalidade nessas ações. O fato de minha mãe ser uma moradora conhecida no bairro (e até mesmo por se tratar de uma senhora com mais de 70 anos) contribuiu para quebrar qualquer desconfiança que pudesse ser gerada pela minha presença num primeiro momento. 
ão podemos deixar de registrar que a pesquisa realizou-se em um bairro do Rio de Janeiro, município no qual a população tem convivido, cotidianamente, com o medo, com a insegurança e, conseqüentemente, com a desconfiança. Em Vila Valqueire não era diferente.

Não tenho dúvidas de que o contato inicial, ao ser realizado, na maioria dos casos, por D. Ivette, ajudou a superar possíveis resistências das explicadoras e, principalmente, de seus maridos e familiares.

Enfim, definido o grupo: Conceição, Mary, Clarisse, Marcilene, Valéria, Silvana, Maria, Mônica e Rosana.

\section{Os caminhos percorridos (ou as estratégias metodológicas)}

As opções metodológicas assumidas na pesquisa se apresentaram como as mais adequadas para as características de um estudo de inspiração etnográfica.

Definidos os sujeitos, a partir dos critérios estabelecidos como norteadores, procedeu-se a um período de entrevistas exploratórias (agendadas após um ou mais telefonemas feitos por mim a todas as explicadoras), através das quais tornou-se possível, em primeiro lugar, estabelecer uma relação de confiança entre pesquisador e informante, fator de grande importância para um estudo com esse perfil.

Nas entrevistas exploratórias (realizadas durante uma ou duas visitas feitas na casa de cada uma das explicadoras), foi possível, também, explicitar o objetivo do estudo com maior riqueza de detalhes.

Em segundo lugar, de posse dos dados obtidos nas entrevistas exploratórias, foi possível construir e adequar os roteiros utilizados para orientar a observação participante e a entrevista semi-estruturada.

Foram realizadas diversas visitas à casa de cada explicadora, ${ }^{5}$ durante as quais pude observar o ambiente físico do trabalho (salas, varandas etc.), as estratégias didático-pedagógicas, os materiais didáticos utilizados, a dinâmica das aulas, as relações entre as explicadoras e os alunos e entre elas e os responsáveis dos alunos, a indumentária usada pelas professoras e pelos alunos, etc.

Captar a especificidade do ofício de explicadora e, ao mesmo tempo, as particularidades e recorrências no universo de cada uma das nove informantes foi um exercício factível, em virtude das possibilidades criadas por essa estratégia metodológica.

Segundo Becker (1999, p. 47),

As visitas eram realizadas durante todo o dia de trabalho das explicadoras (manhã, tarde e noite), somente havendo intervalo para o almoço.

O observador participante coleta dados através de sua participação na vida cotidiana do grupo ou organização que estuda. Ele observa as pessoas que está estudando para ver as situações com que se deparam normalmente e como se comportam diante delas. Entabula conversação com alguns ou com todos os participantes desta situação e descobre as interpretações que eles têm sobre os acontecimentos que observou. 
Na penúltima (em alguns casos) ou na última visita (na maioria das vezes), foram realizadas as entrevistas semi-estruturadas.

A ferramenta metodológica utilizada para obter os depoimentos das explicadoras teve o relato oral como norteador; isso porque as questões presentes na segunda etapa das entrevistas, na sua grande maioria, foram formuladas de maneira a possibilitar a liberdade das informantes para respondê-las, estimulando e transformando as narrativas das explicadoras no elemento central de suas entrevistas.

Por intermédio das questões, as explicadoras tiveram condições de realizar longos depoimentos, recorrendo, de forma sistemática, às suas memórias.

Pollak (1989, p. 13) destaca que "Através desse trabalho de reconstrução de si mesmo o indivíduo tende a definir seu lugar social e suas relações com os outros."

Entretanto, esse recurso metodológico, por mais flexível que possa parecer, não abriu mão da intencionalidade na condução das entrevistas. Como nos revela Brandão (1999, p. 8),

Definitivamente, a flexibilidade sempre reclamada para as entrevistas (não estruturadas) não têm nada a ver com uma conversa. A entrevista é trabalho, reclamando uma atenção permanente do pesquisador aos seus objetivos, obrigando-o a colocar-se intensamente à escuta do que é dito, a refletir sobre a forma e conteúdo da fala do entrevistado, os encadeamentos, as indecisões, contradições, as expressões e gestos.... [grifo da autora].

Pois bem, a quantidade de informações e a densidade dos relatos obtidos durante o período do campo foram de tal ordem que o caderno de campo e as transcrições das inúmeras fitas se transformaram em potentes aliados na interpretação dos dados.

Uma estratégia adotada na construção do relatório final da pesquisa foi a de reservar considerável espaço para a apresentação de cada uma das explicadoras - não uma apresentação pura e simples, mas sim algo que possibilitasse revelar os encontros e desencontros nos cotidianos, nas práticas e nas trajetórias de todas as nove professoras.

O desenvolvimento dessa estratégia serviu não somente para tornar pública essa forma peculiar de exercer a docência, mas, também, para dar contornos mais definidos ao cenário pesquisado, ou melhor, trouxe à tona os principais achados dessa pesquisa.

Dediquemo-nos a eles a partir de agora.

\section{Como constituir-se professora e explicadora}

Uma das questões centrais a ser respondida pela pesquisa referia-se a como se deram os processos de socialização profissional (professora e explicadora) de cada uma das informantes: suas trajetórias escolares, o nível de escolaridade de seus familiares, as influências e os motivos das 
escolhas quando do término do ginásio, o ingresso no curso Normal ou no ensino superior, os primeiros flertes com a docência; enfim, elementos constitutivos e balizadores de opções e representativos da vida de cada uma das professoras. ${ }^{6}$

Para dar conta de tratar dos processos de socialização das minhas nove informantes, no que diz respeito às suas escolhas voltadas para o campo da docência, recorri aos conceitos de habitus e estratégia desenvolvidos por Pierre Bourdieu e interpretados de maneira ajustada à pesquisa através de Nogueira (1991, 2004), Lelis (1996) e Perrenoud (1997).

Todos os três autores têm em suas respectivas produções consultadas um bom caminho andado nas reflexões sobre os processos de socialização de professores, frutos de diálogos com a obra do sociólogo francês Pierre Bourdieu, com trabalhos que, se não se debruçam sobre a realidade da educação brasileira, possuem interfaces extremamente potentes para interpretá-la, como é o caso de Perrenoud (1997).

Portanto, para compreender os processos de socialização das nove explicadoras, fez-se necessário que nos muníssemos de uma espécie de lente bifocal. Explico melhor: focar, nos depoimentos das professoras, elementos constitutivos dos seus processos de socialização familiar e escolar exigiu do meu olhar uma capacidade de leitura fortemente marcada por esses dois conceitos fundantes dos estudos de Bourdieu.

Pela natureza do objeto da pesquisa e dos sujeitos que a compuseram, não seria prudente, sob o ponto de vista teórico, desconsiderar a potência desses recursos, sob pena de ser realizada uma interpretação empobrecida da realidade investigada.

Para Nogueira (1995, p. 3),

O conceito de habitus com a intenção de ultrapassar a oposição determinismo/liberdade através da articulação das estruturas objetivas externas com as estruturas subjetivas internas (a história pessoal), constituindo o ponto de convergência no qual a exterioridade se interioriza e se "incorpora" de modo durável no corpo, exteriorizando-se na forma de disposições, predisposições, propensões, inclinações. Ele funciona como um princípio gerador e organizador das práticas, dos discursos, das representações, tanto no nível do agente quanto no nível do grupo ou classe social.

Da mesma forma, para a autora,

Outro conceito importante da teoria bourdieusiana, o conceito de estratégia - fundamental para a compreensão da teoria dos "campos" - também foi criado com a intenção de se opor ao objetivismo estruturalista (a ação sem sujeito). Ele se refere a um "sentido prático" que advém da participação no "jogo" que se joga nos diferentes campos sociais, em torno da apropriação/manutenção das espécies de capital específicas de cada campo. Assim, ao invés de submissão a regras explícitas, as ações são concebidas como participação no jogo, sendo bom jogador aquele que adquiriu o "sentido do jogo", que "faz a todo instante o que deve ser feito, o que o jogo demanda e exige" (Nogueira, 1991, p. 81).

${ }^{6}$ Sobre socialização profissional no magistério, ler Lelis (1996), Nogueira $(1991,2004)$ e Perrenoud (1997).
Nesse sentido, foquei e interpretei as trajetórias das explicadoras na direção do magistério, quando ainda adolescentes, partindo da mesma 
compreensão que Lelis (1996, p. 64) desenvolveu em sua pesquisa com treze professoras:

[...] as entradas no magistério foram construídas sob determinadas condições. Condições que expressam espaços nos quais estas mulheres transitaram, desde a primeira socialização, e que foram importantes na constituição de disposições mais ou menos favoráveis ao magistério, mais ou menos duradouras. Campo familiar, campo escolar, atravessados por idéias e valores onde estas mulheres ocuparam determinadas posições.

No caso das nove explicadoras, estávamos de frente para dois tipos de escolha: a primeira relacionada com a entrada no curso Normal, o que não significava dizer que era o mesmo que a entrada para o exercício do magistério; a segunda escolha, ou decisão, relaciona-se com o fato de terem optado por trabalhar como explicadoras, ou melhor, por exercerem a docência doméstica, fora do mundo escolar, isto porque quase todas elas tiveram pequenas passagens por escolas, na maioria das vezes em virtude da exigência das horas da disciplina responsável pelo estágio em seus respectivos cursos de formação.

Portanto, essas duas ordens de escolha - pelo magistério e, dentro do próprio magistério, a de ser explicadora - estavam encharcadas de motivos, disposições e estratégias constituídas na história de cada uma das professoras.

De acordo com Lelis (1996, p. 65),

O que estas mulheres revelaram em seus depoimentos foi uma pluralidade de sentimentos e práticas tendo como pano de fundo contextos sociais determinantes nos momentos que antecederam uma escolha e a entrada na profissão e uma série de estratégias desenvolvidas no percurso de suas vidas, ainda na infância e adolescência. [grifo da autora]

\section{A constituição dos eixos temáticos}

Inicialmente organizados no segundo bloco do roteiro da entrevista semi-aberta, sob o título de "Dados relacionados ao ofício de explicadora", destinados a captar aspectos vinculados às práticas cotidianas das nove explicadoras, tornou-se necessário, no decorrer do trabalho de campo, que eles (os dados) passassem a ter um tratamento mais sofisticado.

Penso ser importante chamar a atenção para essa estratégia metodológica, uma vez que ela, de alguma maneira, revelou a importância que a empiria exerceu sobre o conjunto do estudo.

Constituir eixos temáticos, se por um lado teve intenções organizativas, por outro lado serviu para consolidar características presentes no exercício do ofício de explicadora, dando-lhes nomes e foco.

Portanto, falar de estratégias didáticas, rotinas, recursos pedagógicos acionados, relação e opinião sobre família, escola e aluno, desejos e diferenças que marcavam o trabalho da explicadora passou a ser, a partir da estruturação dos eixos, falar sobre a essência daquele ofício. 
Certo de que "todo cuidado é pouco" em um momento como esse na pesquisa, não posso me privar, entretanto, de declarar a fertilidade que essa etapa do estudo adquiriu.

Falar de uma prática até então silenciada nas pesquisas do campo da Educação exigiu um esforço teórico de diálogo com produções que ao menos tangenciassem o tema pesquisado.

Em virtude disso, foi de fundamental importância a interlocução com os estudos de Tardif (2002, 2005), Lelis (1996) e Perrenoud (1997), os quais possibilitaram dar forma aos dados que emergiram com potência do campo, forjando, então, a organização dos eixos temáticos.

O primeiro deles expôs as estratégias didáticas construídas e utilizadas pelas explicadoras no cotidiano de suas aulas. Tanto os procedimentos como os materiais pedagógicos fizeram parte do elenco de iniciativas ao qual elas recorriam para dar conta das demandas dos alunos.

Foi lá que conhecemos o "caderno da explicadora" e reencontramos a tabuada, o ditado e o caderno de caligrafia, todos figuras comuns nas salas e varandas de aulas.

As rotinas constituídas pelas explicadoras para cumprirem a contento suas tarefas emergiram como o segundo eixo da pesquisa.

Organizar o tempo de suas aulas para darem conta dos infindáveis deveres de casa, das dúvidas que precisavam ser resolvidas com vista às provas e testes semanais das escolas, das pesquisas que precisavam ser feitas nos prazos marcados, enfim, todas elas eram situações que exigiam iniciativas forjadas sob forma de rotinas.

Algo que se configurava no ambiente escolar formal como negativo, as rotinas, que Perrenoud (1997) vinculava ao habitus profissional, ao inconsciente e aos automatismos dos professores, no caso das explicadoras, poderíamos dizer que eram um "mal necessário".

O terceiro eixo apresentou-nos aos recursos acionados pelas explicadoras para que pudessem dar conta da diversidade das demandas oriundas de turmas multisseriadas, como as atendidas por elas.

Além dos livros didáticos, sempre presentes como um dos mais acionados, a maioria das professoras revelou que os saberes forjados a partir de suas experiências se configuravam como seu principal recurso para trabalharem com tamanha variedade de demandas.

Para Tardif, Lessard e Lahaye (1991, p. 220),

[...] esses saberes brotam da experiência e são por ela validados. Eles incorporam-se à vivência individual e coletiva sob a forma de habitus e de habilidades, de saber fazer e de saber ser. Podemos chamá-los de saberes da experiência ou da prática.

É certo que elas validaram suas práticas como geradoras de saberes seus relatos comprovaram isso. Pesaram, também, para algumas delas, os saberes construídos em suas trajetórias escolares, principalmente quando deram as primeiras caminhadas na direção da docência doméstica.

Quanto ao quarto e quinto eixos temáticos, foi possível usá-los como termômetros para aferirmos como andavam as relações e as opiniões das 
nove professoras com respeito à instituição escolar, à instituição familiar e aos alunos. Se os resultados apontaram para relações um tanto conturbadas em suas falas sobre os três temas, esse aspecto ficou fortemente evidenciado ao expressarem suas opiniões sobre eles.

Balizadas por um passado não muito preciso, no qual tanto famílias como escolas e alunos se enquadravam em um perfil idealizado ou monumentalizado, todas as explicadoras, sem exceção, foram portadoras de críticas severas à falta de parceria das famílias na condução da educação escolar das crianças, à inadequação dos métodos e da organização escolar e ao descompromisso dos alunos com os estudos.

Juntou-se a essas, mais uma série de pesadas críticas aos professores das escolas, segundo elas pela falta de responsabilidade deles para com a individualidade dos alunos no processo ensino-aprendizagem.

As diferenças presentes no modelo de trabalho doméstico das explicadoras se configuraram como o sexto eixo temático. Certamente que, para falarmos em diferenças, elas foram pensadas em relação a alguma coisa.

Pois bem, a escola era o outro lado da moeda.

O eixo trouxe à superfície o que, na opinião das explicadoras, fazia a diferença para que os alunos aprendessem com elas o que não conseguiam aprender nas respectivas escolas.

Figurou como principal elemento a atenção individualizada, ou como Marta (uma das explicadoras) preferia falar: "o tratamento vip" dispensado aos alunos nas salas e varandas das explicadoras.

Fomos buscar, então, nos estudos de Tardif (2005), Perrenoud (1997) e Penteado (2001), diálogos capazes de darem consistência a mais esse achado da pesquisa.

No caso do autor canadense Tardif, reforçamos o caráter interativo da profissão docente; Perrenoud apresentou-nos, através de um diálogo com Morin, as particularidades e complexidades de profissões com caráter relacional, como é o caso do magistério; por último, Penteado apontou o peso e a importância da comunicação na relação professor/aluno/conhecimentos. Enfim, todos diálogos que contribuíram para dar solidez a um produto desse estudo, produto esse que veio a se configurar como uma das marcas fortes do ofício de explicadora.

Por derradeiro, o sétimo eixo temático: os sonhos e desejos das nove professoras.

A intenção, inicialmente, nas entrevistas, era captar o que poderia aflorar como vontades ainda a serem alcançadas por mulheres professoras. A força dos relatos e alguns paradoxos elevaram a sua importância.

Boa parte dos desejos se limitava ao campo da docência: algumas pretendiam fazer o curso superior na área de Matemática, outras desejavam passar em concurso para lecionar no magistério público. O interessante é que era no magistério que seus sonhos miravam. Mesmo que fosse para trabalhar nas instituições marcadas por suas mais severas críticas.

Portanto, eram essas as explicadoras que o título da pesquisa anunciara.

Foi o silêncio em torno delas que me mobilizou para estudá-las e para torná-las públicas. 


\section{Alguns outros importantes achados da pesquisa}

É de bom tamanho, também, apresentar dois outros importantes achados produzidos pelo estudo.

Trata-se, em primeiro lugar, de resgatarmos as estratégias de evitamento de conflitos com as escolas assumidas pelas explicadoras em suas práticas e em seus relatos. Tal procedimento revelou, além das próprias estratégias, uma postura conservacionista das professoras na direção da instituição escolar; de fato, por mais críticas que fossem aos métodos e procedimentos adotados nas escolas de seus alunos (e não foram poucas as críticas), isso não foi suficiente para que elas (as explicadoras) experimentassem ações mais arrojadas que enfrentassem as dinâmicas tradicionais daquelas instituições.

Um segundo achado se constituiu como revelador de uma realidade não prevista no início da pesquisa. Falo aqui da predominância da freqüência de alunos de escolas particulares nas salas, varandas e quintais de aulas das explicadoras.

Para as professoras, esse dado não significava a superioridade da qualidade da escola pública em relação às instituições privadas. Todas, sem exceção, creditaram ao empobrecimento das camadas menos favorecidas da população, as quais têm feito uso em maior proporção do sistema público de ensino, o fato de não terem condições de pagar (por mais barato que fosse) os preços por elas cobrados. Nesse sentido, eram as famílias com melhores condições financeiras que tinham, na maioria das vezes, acesso aos serviços das explicadoras.

Mas não só de achados e resultados acadêmicos essa pesquisa se nutriu. Algo de importante aconteceu para além do que foi exposto até agora.

\section{Um café da manhã, um encontro e muita história para contar}

Quando iniciei a pesquisa não tinha essa idéia em mente, assim como, também, não imaginava que nenhuma das explicadoras se conhecessem.

E era verdade... Nenhuma delas havia mantido sequer algum contato telefônico, já que quase todas tinham seus números registrados nas "plaquinhas".

A única explicadora que me revelou ter feito ligações para algumas explicadoras do bairro foi Valéria, com a intenção, segundo ela, de fazer um levantamento do preço cobrado pelas suas (na época) futuras concorrentes.

Sempre tratei desse tema com cuidado com elas, qual seja, o de procurar saber se conheciam outras explicadoras no bairro e, se não, por que não conheciam.

Para a primeira pergunta as respostas eram negativas e para a segunda, geralmente, nenhum motivo justificável.

Por entender, exatamente, que poderia avançar por um terreno não desejável - o da disputa de espaço ou da concorrência -, nunca insisti nesse tema.

Entretanto, passei a nutrir a vontade de realizar um encontro onde todos nós, participantes da pesquisa, pudéssemos estar: eu, D. Ivette e todas as nove explicadoras, para que tivéssemos a oportunidade de nos 
apresentar e conversar de maneira informal sobre a pesquisa e sobre o que fosse do interesse no momento. Esse foi o primeiro desenho em minha imaginação.

Com o tempo e conversando com elas o projeto foi se desenvolvendo, e cheguei ao formato de um café da manhã, a ser realizado em um sábado do mês de novembro de 2005 (quando o número de alunos já estava menor), onde iríamos ter dois momentos: o primeiro destinado às apresentações e à confraternização propriamente dita, e o segundo, no qual realizaríamos uma roda de bate-papo, onde conversaríamos sobre aluno, família, escola e sobre ser explicadora.

Contratei uma equipe de documentaristas do Centro de Educação e Imagens Populares (Cecipe) ${ }^{7}$ para registrar o encontro, e informei a todas elas, por meio de convite e de telefonemas, que esse evento seria gravado. No dia não foram todas.

Na véspera, Rosana, Marcilene e Marta avisaram-me que não poderiam estar, por motivos de saúde, familiares e de compromisso com a catequese, respectivamente.

Entretanto, todas as outras, Conceição (anfitriã), Mônica, Mary, Valéria, Clarisse e Silvana, foram chegando, aos pouquinhos. Todas bem arrumadas e maquiadas.

Depois das apresentações conversamos durante, aproximadamente, uma hora, lanchamos e formamos um círculo, para dar inicio, então, à segunda parte do encontro.

Chamaria a atenção para três aspectos que emergiram do bate-papo:

O primeiro relacionado ao fato de que me impressionou como ganharam volume, quando feitas em conjunto, as críticas tecidas por elas, especificamente sobre as famílias e as escolas e, em especial, aos professores das escolas; todas, sem exceção, conseguiram ser mais duras do que nas entrevistas, quando falaram da falta de responsabilidade das famílias e dos professores em relação aos alunos.

O segundo aspecto que me chamou a atenção foi quando elas falaram delas, ou melhor, sobre o papel delas. Afirmações do tipo "A escola é pra passar; a gente pra explicar", "A criança vai para a explicadora porque as famílias querem se livrar dos compromissos", "A escola tem que reconhecer que precisa da explicadora" etc. se juntaram a outras que revelavam o prazer de exercerem esse ofício: "É gratificante quando o aluno chega pra você e fala: 'Pôxa tia eu consegui isso ou aquilo"', "Meus alunos me procuram até hoje", "É muito bom uma senhora de setenta e quatro anos que eu ensinei a assinar o nome, a escrever e a ler" etc.

A fala coletiva também foi provocadora de uma força na defesa do ofício de explicadora e que ganhou contornos corporativos, vistos com menor intensidade durante as entrevistas individuais.

Por último, fiz questão de dar foco a um fragmento do depoimento de Clarisse, que, já próximo do final do encontro, pediu a palavra para reconhecer que, no início da pesquisa, quando eu havia feito os primeiros contatos, ela se esquivara de me atender, mas que naquele momento se sentia "muito feliz de saber que tinha alguém interessado no trabalho das explicadoras".
${ }^{7}$ ONG que trabalha com cursos de imagens e documentários nas áreas de Educação e Educação Popular. 
Vejo-me diante, portanto, de uma pesquisa que ousa contribuir com os estudos do campo da História da Profissão Docente, sobre os quais Nunes (apud Catani, 2003) já denunciara a ausência de traços demarcadores desse campo específico de pesquisa.

Acredito, com a humildade necessária, que o presente estudo inaugura uma temática que pode ser absorvida pelo referido campo. Afinal de contas, as explicadoras incorporam histórias de um tipo de exercício da docência e sobre o qual já podemos dizer que conhecemos um pouco.

Enfim, penso ter contribuído com as pesquisas do campo da Educação, ou, talvez, tal qual fala António Nóvoa, esteja a pagar - quem sabe? parte da dívida com o meu passado através deste estudo.

\section{Referências bibliográficas}

BECKER, Howard S. Métodos de pesquisa em ciências sociais. Trad. Marco Estevão e Renato Aguiar. São Paulo: Hucitec, 1999. 178 p.

BRANDÃO, Zaia. Entre questionários e entrevistas. Rio de Janeiro: PUCRio, 1999. (Mimeogr.).

CHARLOT, Bernard. Da relação com o saber: elementos para uma teoria. Trad. Bruno Magne. Porto Alegre: Artes Médicas Sul, 2000. 93 p.

CATANI, Denice Bárbara. Estudos da história da profissão docente. In: LOPES, Eliane Marta T.; FARIA FILHO, Luciano Mendes de; VEIGA, Cynthia Greive. 500 anos de educação no Brasil. 3. ed. Belo Horizonte: Autêntica, 2003. p. 584-599.

LELIS, Isabel Alice Oswald Monteiro. A polissemia do magistério: entre mitos e histórias. 1996. Tese (Doutorado) - PUC-RJ, Departamento de Educação, 1996.

LOPES, Eliane Marta T.; FARIA FILHO, Luciano Mendes de; VEIGA, Cynthia Greive. 500 anos de educação no Brasil. 3. ed. Belo Horizonte: Autêntica, 2003. 608 p.

NOGUEIRA, Maria Alice. Trajetórias escolares, estratégias culturais e classes sociais: notas em vista da construção do objeto de pesquisa. Teoria e Educação, Porto Alegre, n. 3, p. 89-112, 1991.

Convertidos e oblatos: um exame da relação classes médias/ escola na obra de Pierre Bourdieu. 1995. (Mimeogr.).

Bourdieu e a educação. Belo Horizonte: Autêntica, 2004. 152 p. 
NÓVOA, António. O espaço público da educação: imagens, narrativas e dilemas. In: PROST, Antoine et al. (Eds.). Espaços de educação, tempos de formação. Lisboa: Fundação Calouste Gulbenkian, 2002. p. 237-263.

PATTO, Maria Helena Souza. A produção do fracasso escolar: histórias de submissão e rebeldia. São Paulo: Casa do Psicólogo, 1999. 462 p.

PENTEADO, Heloísa Dupas (Org.). Pedagogia da comunicação: teorias e práticas. 2. ed. São Paulo: Cortez, 2001. 222 p.

PERRENOUD, Philippe. Práticas pedagógicas, profissão docente e formação: perspectivas sociológicas. 2. ed. Lisboa: Publicações Dom Quixote, 1997. $212 \mathrm{p}$.

POLLAK, Michael. Memória, esquecimento, silêncio. Estudos Históricos, Rio de Janeiro, v. 2, n. 3, p. 3-15, 1989.

TARDIF, Maurice; LESSARD, Claude; LAHAYE, Louise. Os professores face ao saber: esboço de uma problemática do saber docente. Teoria e Educação, Porto Alegre, n. 4, p. 215-233, 1991.

TARDIF, Maurice. Saberes docentes e formação profissional. Petrópolis: Vozes, 2002. 328 p.

O trabalho docente: elementos para uma teoria da docência como profissão de interações humanas. Petrópolis: Vozes, 2005.

Luiz Otavio Neves Mattos, doutor em Educação pela Faculdade de Educação da Universidade de São Paulo (USP), é professor das redes pública e privada do Estado do Rio de Janeiro. Atualmente exerce a função de assessor especial da Secretaria Nacional de Desenvolvimento do Esporte e do Lazer do Ministério do Esporte.

nevesmattos@ig.com.br

Recebido em 4 de julho de 2006.

Aprovado em 17 de novembro de 2006. 